\title{
DIFICULDADES DE MECANIZAÇÃO AGRÍCOLA NA AGRICULTURA FAMILIAR BRASILEIRA
}

\author{
Winny Silva Trugilho' \\ Bruno Fardim Christo ${ }^{2}$ \\ Gabriel Mancini Antunes da Silva ${ }^{3}$ \\ Fernanda Dassie Rangel ${ }^{4}$ \\ Elaine Cristina Gomes da Silva ${ }^{5}$
}

Resumo: A produtividade do setor agrícola brasileiro e a oferta do produto final ao mercado consumidor estão diretamente relacionadas com a mecanização em todas as etapas do processo produtivo. No entanto, poucos agricultores familiares possuem acesso à mecanização agrícola devido alto custo do investimento inicial. O presente trabalho descreve as principais dificuldades para a implementação de máquinas agrícolas na agricultura familiar e os principais problemas da mecanização. Contudo, pôde-se observar que a mecanização é pouco empregada pelos agricultores familiares, no entanto, as patrulhas agrícolas possibilitam o emprego de máquinas pelos pequenos agricultores.

Palavras-chave: Máquinas agrícolas; Pequenos agricultores; Custos operacionais.

\footnotetext{
1 Mestrado em Produção Vegetal/Universidade Estatual do Norte Fluminense Darcy Ribeiro, Brasil. E-mail: winnytrugilio@hotmail.com.

2 Agronomia/Universidade Federal do Espírito Santo, Brasil. E-mail: brunochristo@hotmail.com.

${ }^{3}$ Eng. Florestal/Universidade Federal do Espírito Santo, Brasil. E-mail: twilight.mancini@hotmail.com.

4 Eng. Química/Universidade Federal do Espírito Santo, Brasil. E-mail: fernanda.dassierangel@gmail.com.

${ }^{5}$ Ciências Florestais/Universidade Federal do Espírito Santo, Brasil. E-mail: ecristinags@gmail.com.
} 